\title{
Modelling and Simulation of Below-the-Hook Lifting Device Balanced C-hook for Load to Investigate the Static and Model Analysis for Various Grades of Steels by Numerical Method
}

\author{
Mahanthesh M R, Girisha L, Malteshkumar Deshpande, Shreyas Babu, Shivananda DC \\ PES Institute of Technology and Management, Shivamogga.
}

* Corresponding author email: mahanthesh.mr@pestrust.edu.in

Received: 28 May 2020 / Revised: 26 June 2020 / Accepted: 07 July 2020 / Published: 07 July 2020

\begin{abstract}
Below-the-Hook Lifting Devices will enable easy loading, unloading and transportation of heavy metal coils. A balanced c-hook is one of the widely used Below-the-Hook Lifting Devices works by inserting its lower arm inside the hole of coil. Multiple variations of c hooks are being used based on different load requirements, and different applications like paper roll c hooks to transport heavy paper rolls, spring loaded c hooks to reduce weight by avoiding counter weights etc. Structural and mechanical lifters may be modified or reassessed, provided that such alterations are analyzed and approved. Balanced c-Hook are to be designed by considering forces imposed by the lifted load, the weights of the device's parts, since balanced c hooks are subjected repeated loading and unloading, there is probability of failure due stress concentration. To prevent chances of failure, Prior study is required on this; the materials which are generally used for the $\mathrm{C}$ hook are considered for a particular loading condition of 10 Tons, Design of the bellow the hooks is done by numerical method. Modeling and Simulations are carried to determine the various factors like deformation, stresses generated and mode shapes. The comparison among all the selected materials is done to check the suitability of the material to use as a balanced $\mathrm{C}$ hook. For the generation of $\mathrm{CAD}$ model of $\mathrm{C}-$ Hook various geometrical features and Dimensions are selected as per the specification from ASME B30.20 standard. To investigate statics stress results and model are obtained from Finite element Method. from the results of the analysis it is observed that results obtained are in close match with each other and maximum stress concentration occurs at inner most surface.
\end{abstract}

Keywords: C-hook, ANSYS, CATIA V5, Modelling, Simulation

\section{Introduction}

A balanced c-hook is an additional attachment, attached to cranes using conventional crane hook. The structural lifting system consists of a rigid framework assembly built to support and connect the load to a heavy-duty lifting unit. and Counter balanced to hang level when not loaded. Complies with ASME standards ASME B30.20 \& BTH-1 figure .1 shows Balanced "c" Hook lifter Picked up from the fig..20-0.35 Load Supporting lifters in ASME B30.20-2010 standard. This specification sets the minimum structural and mechanical design specifications for selecting components for below-the-hook lifting devices from ASME B30.20. The provisions of this Standard also apply to design. It also sets design criteria for Below the Hook Lifting Devices. This Standard serves as a guide to designers, lifting devices designed to this Standard shall comply with with ASME standards ASME B30.20 \& BTH-1. It also covers provisions applicable for the testing and operation of lifting devices.[1]

Below the Hook Lifting Devices will enable easy loading, unloading and transportation of heavy metal coils[2]. A balanced c-hook is one of the widely used Below-the-Hook Lifting Devices works by inserting its lower arm inside the hole of coil. C-hooks are normally attached to EOT (electric overhead crane) and other forms of cranes in industries and ports[3]. Failure of balanced c-hook may occur due to following reasons like overloading, plastic deformation, bending stress and tensile stress. The various materials are used to manufacture the crane hooks such includes lead alloy[4]. Structural Steel, High Strength steel, Low 
Alloy Steel [5], Forged Steel, Wrought iron/MS, Aluminium Alloy etc. These materials selection is depend on various factors such as total load to carry, environment, type of loading etc. Before proceeding to the actual working environment, the model is tested in available software tools to analyze its suitability to the required condition and the results obtained from these can be compared numerically [[6]-[8]] it is also helpful to predict life of crane hook by predicting stress concentration area is done. Apart from the regular section some of the application utilizes the as I-Section and T-section which improves the performance. There is a vital component in marine industries which is called as Ramshorn crane hook [9]. The present paper aims at studying the suitability of various materials for the required condition.

Structural and mechanical lifters devices are considered as load supporting lifters, and include a positive connection to the load. The lifting device's rated load shall be marked write properly on its main structure, or on a label attached to its main structure where it is visible. Structural and mechanical lifters may be altered or rerated, provided such alterations are analyzed and approved by the equipment manufacturer[8]. During Inspection of structural members for deformation, cracks, or excessive wear on any part of the lifter[10]. Deformation of the hook can be an indication of overload or improper usage techniques. It may be apparent in some cases that the hook gets deformed, Because of undue wear or corrosion on the hook, this means that the hook should be detached from service. Hooks are subject to fatigue failure, Abnormal operating conditions which are unfavorable environmental conditions, or Harmful to using a hook, Crack due to discontinuity in the material of a cavity type [11], [12].

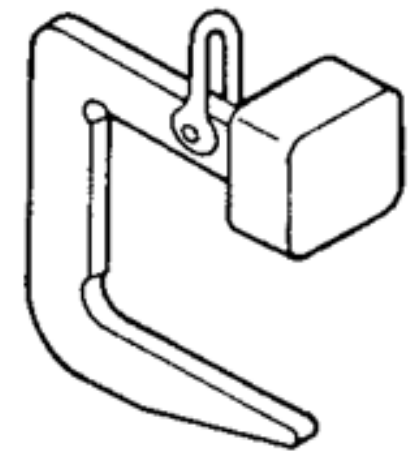

Figure 1: Balanced C-Chook Lifter

\section{Methodology}

In the industries $\mathrm{c}$ hooks are among the key components for material handling and Movement. $\mathrm{C}$ hooks are components susceptible of failure due to stress in heavy load accumulation. A balanced C hook failure depends primarily on three major factors i.e. size, overload and material. Methodology fallowed in this work is that an attempt has been made to identify the stress concentration and deflection in balanced c-hook which is attached to the Crane Hook. Effect on different material is analyzed, keeping the design and load similar. The model is created using CATIA V5, and Finite Element Method is performed using ANSYS16. Deflection and von-mises stress are compared for different material of the hook. This paper aims to find results such as Displacement, von-mises stress and Modal analysis of $\mathrm{C}$ hooks for various conditions.

\subsection{Specifications}

Specifications of the C-Hook as per the ASTM Standard is as follows. Also shown in table 1: Specification of C-Hook With reference to the figure 2: Balanced C-Chook with Coil and Specification Sketch.

Weight:400 lbs-1425 lbs

Capacity:5 -10 Ton

Coil Width Max/Min: 36" / 24"- 72" / 42"

Headroom: 38"- 43.3" 
Table 1: Specification of C-Hook

\begin{tabular}{cccc}
\hline Throat & L (in.) & D (in.) & W (in.) \\
\hline $24-$ & $30-57$ & $8-9$ & 4 \\
\hline
\end{tabular}
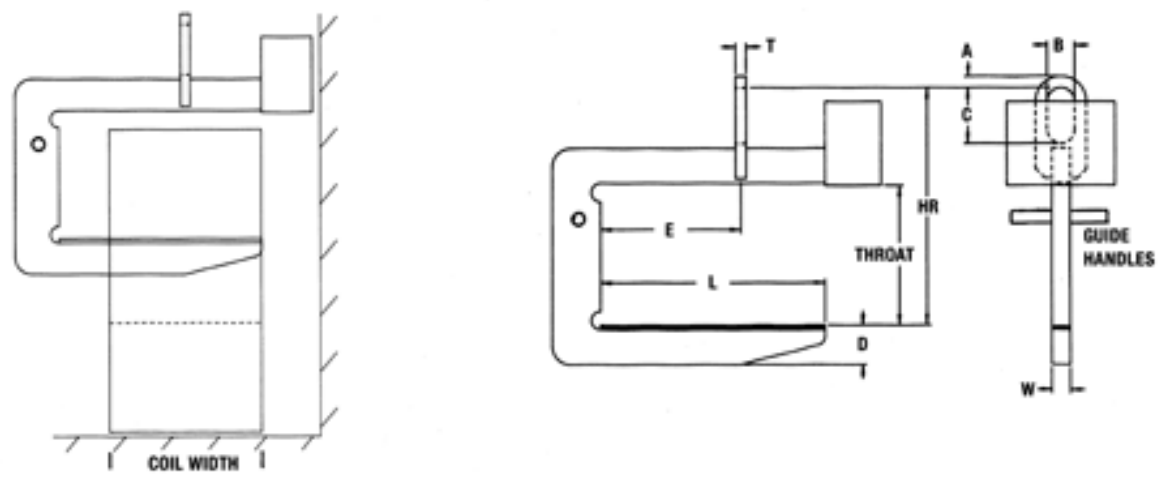

Figure 2: Balanced C-Chook with Coil and Specification Sketch.

\subsection{Design Criteria}

All the below the hooks lifting devices shall be designed for specified rated loads, Load geometry. The Resolution of loads into forces and stress affecting structural elements, mechanical parts, and connections shall be carried out by an accepted analysis method. Design factor to be considered as the ratio between nominal breaking strength and rated load applied to hooks that is the maximum acceptable working load of the hook load, Commonly, the terms rated capacity and working load maximum are used to define rated load [13][14].

\subsection{Analysis Methods}

The allowable stresses and stress ranges defined in ASME Standard are based on the assumption of analysis by classical strength of material methods, although other analysis methods may be used. The analysis techniques and models for the loads, material properties and geometry of the equipment used shall be accurately represented; the stress values resulting from the analysis shall be of the appropriate form to allow correlation with the permissible stresses defined in this ASME Standard[15]. The hook shall be designed to withstand all stresses exerted when handling loads within the rated load under normal operating conditions. The design factor of the hook shall at least conform to those specified for the device or system in which the hook is a component.

\section{Materials and Components}

Cranes have to lift higher loads hence it becomes challenging task to design a perfect hook shape. Selection of perfect materials is also difficult as hooks are available in different materials. The hook material shall have sufficient ductility to permanently deform before losing the ability to support the load at the temperatures at which the specific hook will be used.

This Standard's design specifications are focused on the use of, low-alloy high-strength or heat-treated carbon alloy steel for structural parts and other mechanical components. Other materials may be used, provided the safety and fatigue margins are equal to or greater than those set out in this Standard. All ferrous metal and nonferrous metal can be used in the fabrication of lifting device structural members and mechanical parts are identified industrially or written proprietary specification[12]. The general materials that are used for the $\mathrm{C}$ hooks are studied and the simulation testing is carried out on the same. The selected materials are as shown in Table 2. The hook and hook-securing mechanism shall be of adequate strength and design factor for the load and application valued [16] 
Table2: Materials considered

\begin{tabular}{|l|c|c|c|}
\hline Material & $\begin{array}{c}\text { Density } \\
(\mathrm{kg} / \mathrm{m} 3)\end{array}$ & $\begin{array}{c}\text { Young's Modulus } \\
(\mathrm{GPa})\end{array}$ & Possion's ratio \\
\hline Stainless Steel & 7750 & 193 & 0.31 \\
\hline Structural Steel & 7850 & 200 & 0.3 \\
\hline $\begin{array}{l}\text { ASTM Grade 60 } \\
\text { (Grey Cast Iron) }\end{array}$ & 7500 & 190 & 0.29 \\
\hline
\end{tabular}

\section{Modeling of $\mathbf{C}$ hook}

The structural members and mechanical components of a below the hook lifting device are to be designed for the forces imposed by the lifted load (rated load), any forces such as gripping forces and the weights of the device's parts. For the generation of CAD model of $\mathrm{C}$-Hook various geometrical features and Dimensions are selected from ASME B30.20 as per the specification.

Based on extensive examine CAD model all the individual parts of balanced c-hook are created And Parts are assembled using CATIA V5.

Finite Element Analysis is a numerical method of predicting how a product will respond to real-world forces, vibration, fluid flow, heat, and other physical effects. Finite element method Shows if a product breaks, wears out or works the way it has been designed. It is called analysis but it is used to predict what will happen when the product is used in the process of product development. CAD models of balanced Chook are modelled using CATIA V5 software, then model developed for finite element structural analysis was imported to ANSYS. ANSYS -16 WORKBENCH is a virtual environment consisting of different set of tools, allowing the user to perform specific design tasks as well as analytical tasks in a given field. And therefore Workbench is expected to work[17], [18]

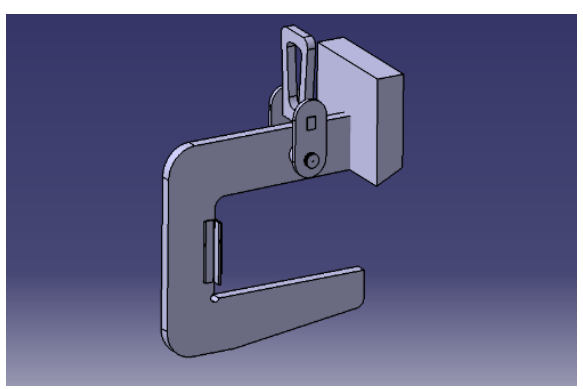

Figure 3: balanced c-hook assembly.

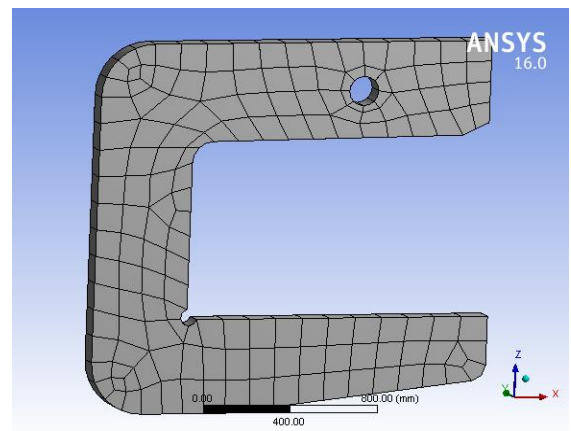

Figure 5: Meshing

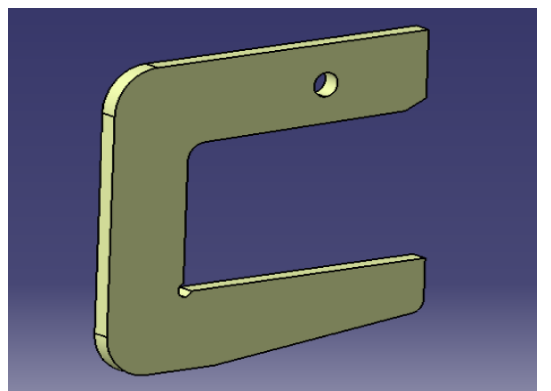

Figure 4: $\mathrm{C}$ frame of balanced c-hook.

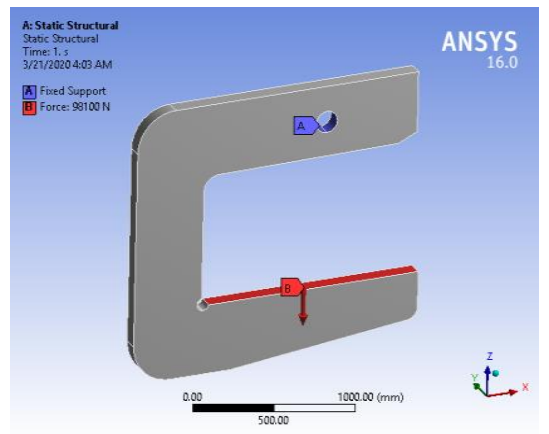

Figure 6: Boundary Condition

The above figure shows the model used for the present study; Figure 3 indicates the balanced c-hook assembly. Figure 4 shows the $\mathrm{C}$ frame of a balanced c hook. Once the model is created it is meshed with regular meshing technique as shown in figure 5 , Based on the understanding of actual vertical loading condition. The boundary conditions are assigned to the model as shown in figure 6 . 


\section{$5 \quad$ Results and Discussion}

Analysis is only performed on the c frame of the assembly. Default meshing is performed on the object. Analysis if performed for materials stainless steel, structural steel and, ASTM Grade-60 (gray cast iron). Only the materials are varied by keeping the design same. A load of 10 Ton is applied and the deformation that occurred for the selected materials are as shown in the figure 7

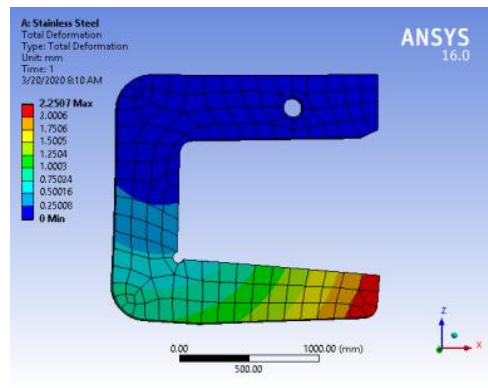

a. Structural steel

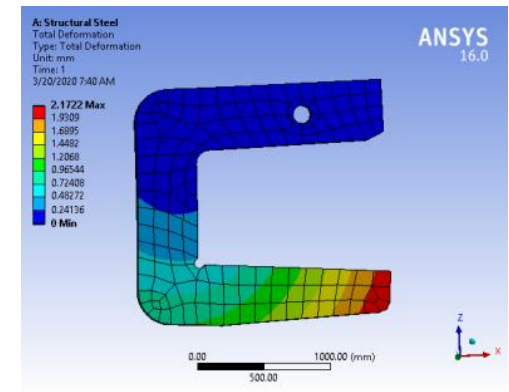

b. Stainless steel

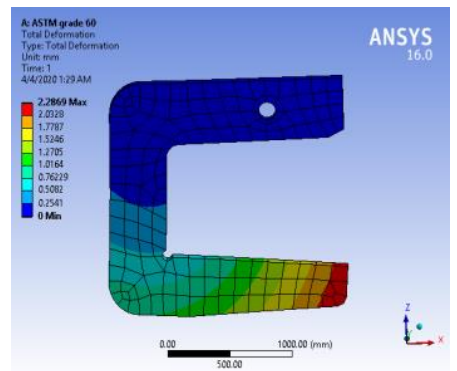

c. ASTM grade 60

Figure 7: Deformation

The stress analysis helps identify where the structures meet expectations and how others can improve. Through carrying out these studies, it helps to create an integrity structure that can withstand the forces exerted on it. In order to analyze the stress pattern for the applied loading condition Von Mises stress is simulated a shown in the figure 8 .

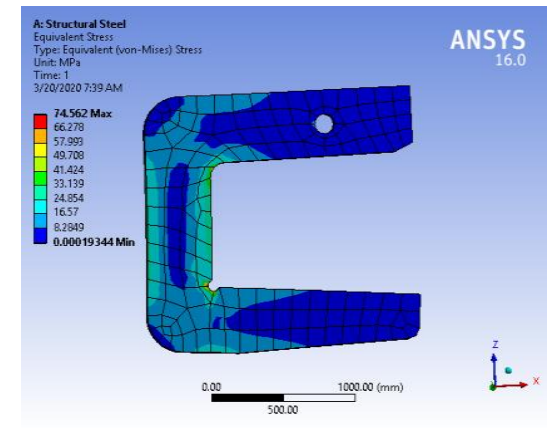

a. Structural steel

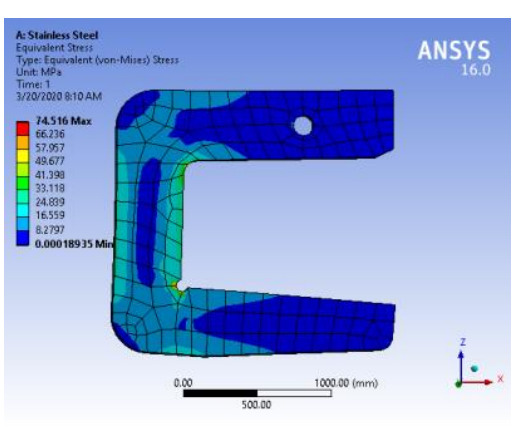

b. Stainless steel

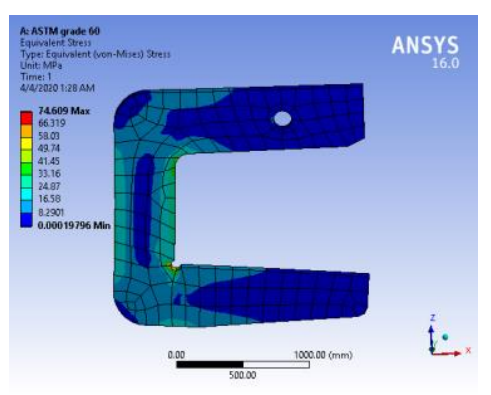

c. ASTM grade 60.

Figure 8: Von mises Stress

The study also extended to understand the vibrational characteristics for the presented model, in order to examine this Mode shapes are calculated. These are as shown in the figure 9, Figure 10 and figure 11 for stainless steel, structural steel and ASTM grade 60 respectively. 
Modelling and Simulation of Below-the-Hook Lifting Device Balanced C-hook for Load to Investigate the Static and Model Analysis..............

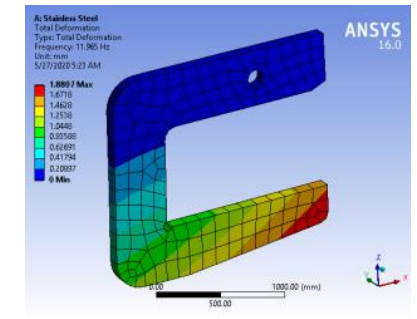

a.

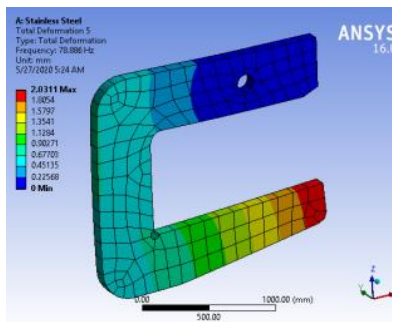

e.

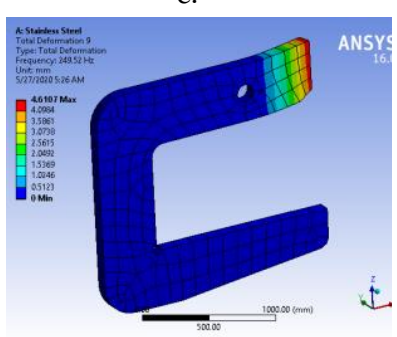

i.

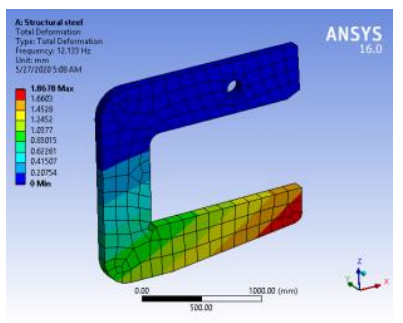

a.

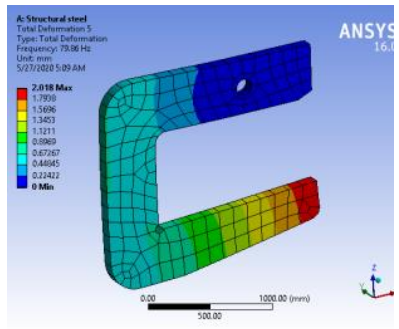

e.

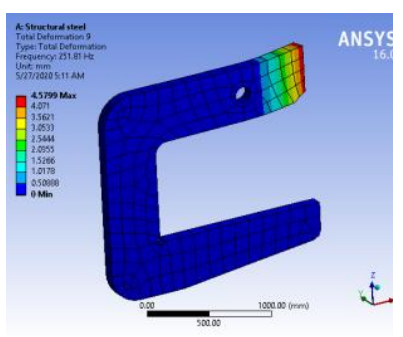

Figure 9: Mode shapes for stainless steel

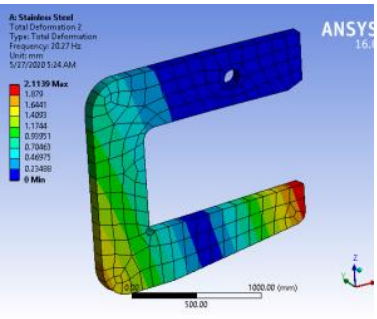

b.

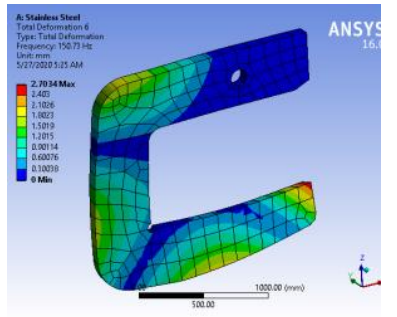

f.

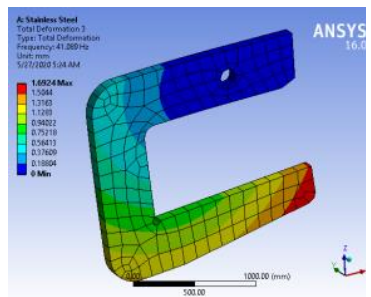

c.

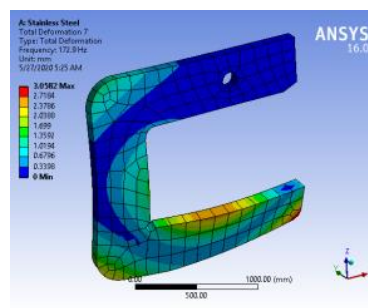

g.

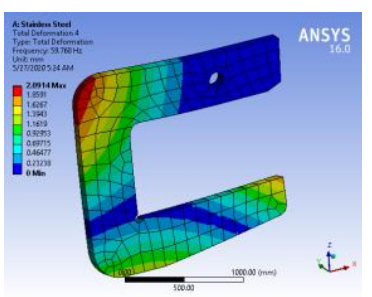

d.

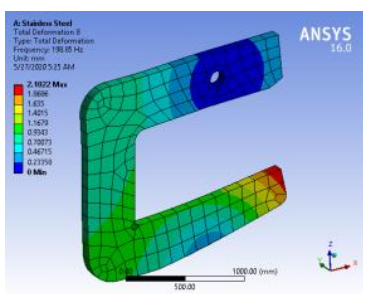

h.

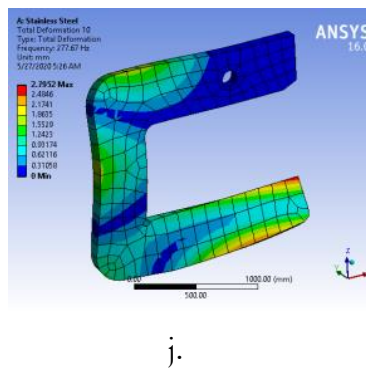

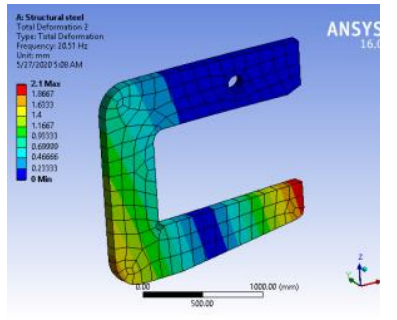

b.

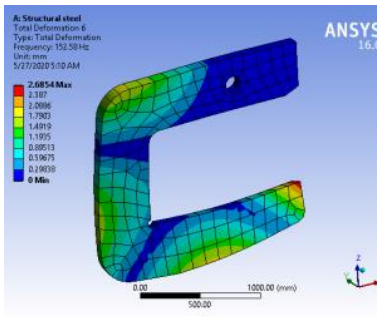

f.

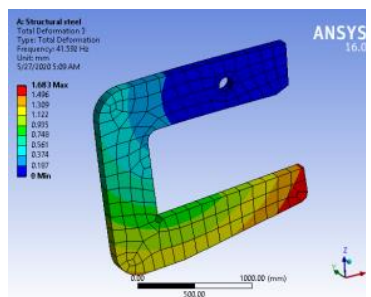

c.

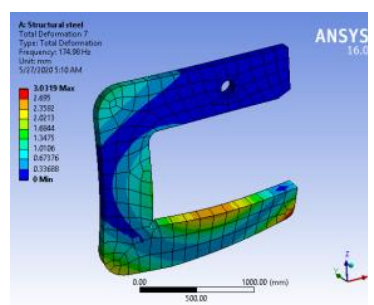

g.

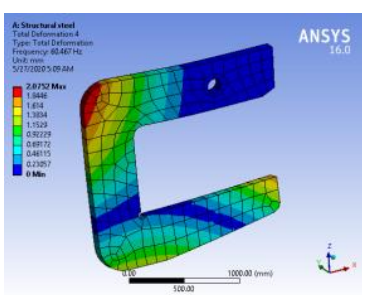

d.

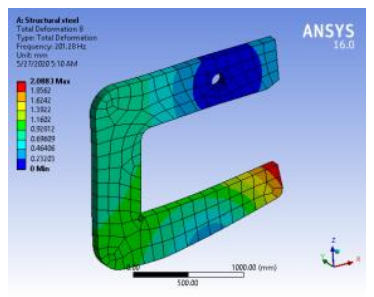

h.

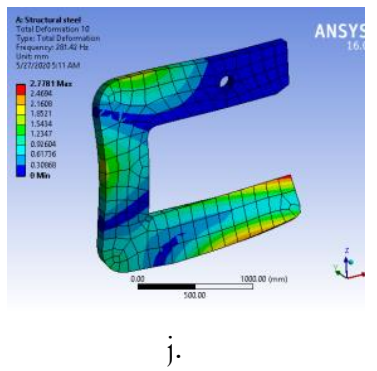

Figure 10: Mode shapes for structural steel 


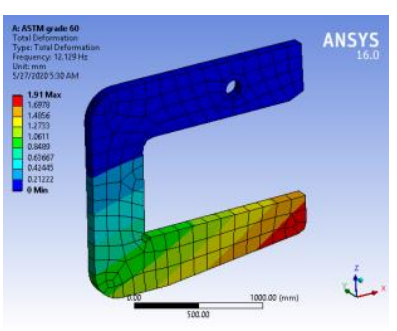

a.

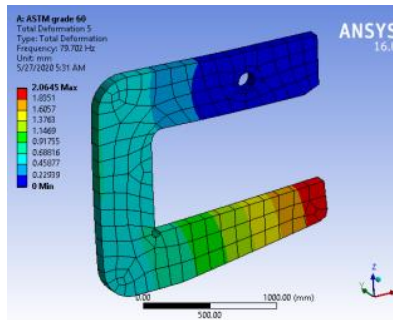

e. 5

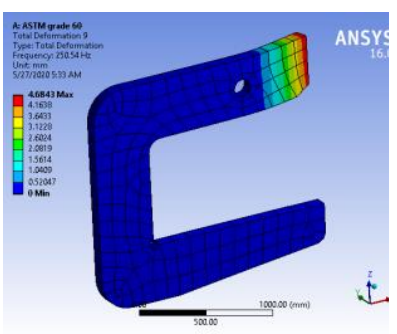

i.

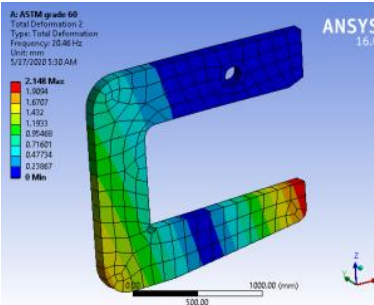

b.

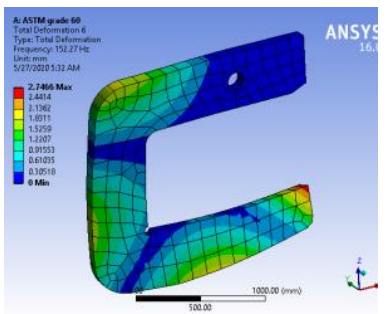

f.

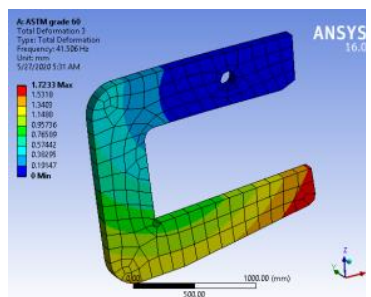

c.

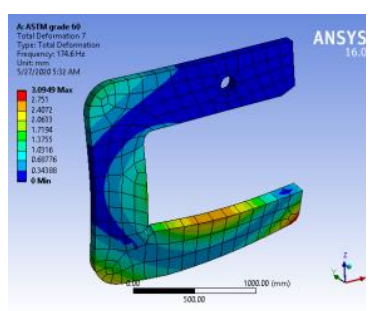

g.

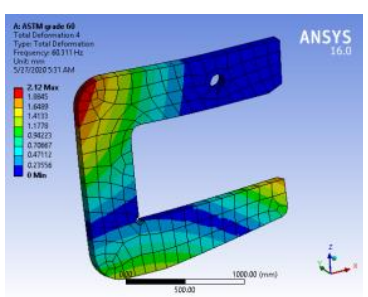

d.

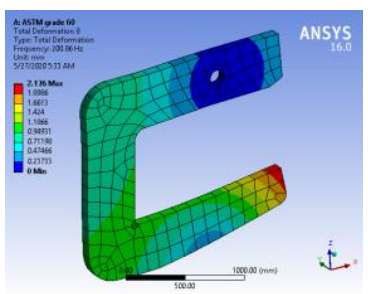

h.

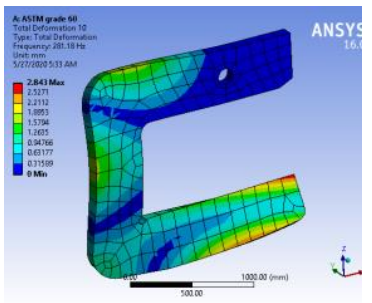

j.

Figure 11: Mode shapes for ASTM Grade 60

Table3: Deformation, Stress, FOS for various materials

\begin{tabular}{|l|c|c|c|c|}
\hline Material & Yield Strength (MPa) & Deformation (mm) & $\begin{array}{c}\text { Von Mises Stress } \\
(\mathrm{MPa})\end{array}$ & FOS \\
\hline Stainless Steel & 250 & 2.1772 & 74.562 & 3.34 \\
\hline Structural Steel & 207 & 2.2507 & 74.516 & 2.77 \\
\hline $\begin{array}{l}\text { ASTM Grade 60 } \\
\text { (Grey Cast Iron) }\end{array}$ & 280 & 2.2868 & 74.604 & 3.752 \\
\hline
\end{tabular}

Based on the analysis the Deformation, Von Mises stress are as tabulated in the Table 3 and it is observed that the and Von mises stresses are more for ASTM Grade 60 in compared to other two. As all the materials are subjected to similar loading condition, by considering the stress generated and the Yield strength those possesses the ASTM Grade 60 is found be having higher Factor of safety in comparison with other two. 
Modelling and Simulation of Below-the-Hook Lifting Device Balanced C-hook for Load to Investigate the Static and Model Analysis...............

Table 4: Natural frequencies in $\mathrm{Hz}$

\begin{tabular}{|c|c|c|c|}
\hline S No & Stainless Steel & Structural steel & ASTM Grade 60 \\
\hline 1 & 11.965 & 12.133 & 12.129 \\
\hline 2 & 20.27 & 20.51 & 20.46 \\
\hline 3 & 41.089 & 41.592 & 41.506 \\
\hline 4 & 59.768 & 60.467 & 60.311 \\
\hline 5 & 78.886 & 79.86 & 79.702 \\
\hline 6 & 150.73 & 152.58 & 152.27 \\
\hline 7 & 172.9 & 174.98 & 174.6 \\
\hline 8 & 198.85 & 201.28 & 200.86 \\
\hline 9 & 249.52 & 251.81 & 250.54 \\
\hline 10 & 277.67 & 281.42 & 281.18 \\
\hline
\end{tabular}

Based on the mode shapes, the Natural frequencies for all the three materials are as shown in above Table 04. As per the observation Natural frequencies for a particular mode shapes are nearly same for Structural and ASTM Grade 60 (Cast Iron) and least for stainless steel among three.

\section{Conclusion}

Structural and mechanical lifters devices are characterized as load supporting lifters, and include a positive connection to the load. The structural members and mechanical components of a below the hook lifting device are to be designed for the forces imposed by the lifted the weights of the device's parts, The balanced $\mathrm{C}$ hook is mainly used to carry the load in industries, in order to study the suitability, The design provisions as per ASTM Standard are based on the use of high strength low-alloy carbon, or heat-treated alloy steel for structural members, various materials are considered for the analysis in work is namely Stainless Steel, Structural steel and ASTM Grade 60, FEA analysis is carried on the same to get the deformation, stress and modal frequencies for all the three. A rated load of 10 Ton is applied and the deformation that occurred for the selected materials. In order to analyze the stress pattern for the applied loading condition Von Mises stress is simulated. it is observed that the and Von mises stresses are more for ASTM Grade 60 in compared to other two. As all the materials are subjected to similar loading condition, by considering the stress generated and the Yield strength those possesses the ASTM Grade 60 is found be having higher Factor of safety in comparison with other two. The study also extended to understand the vibrational characteristics for the presented model, in order to examine this Mode shapes are calculated. The Natural frequencies for a particular mode shapes are nearly same for Structural and ASTM Grade 60 (Cast Iron) and least for stainless steel among three. Based on the numerical analysis result of stresses generated and Modal shapes with frequencies, It's evident that. ASTM grade 60(gray cast iron), is best choice to manufacture balanced c hook.

\section{Competing Interests}

The author declared that no conflict of interest exists in this publication

\section{How to Cite this Article:}

M. M R, G. L, M. Deshpande, S. Babu C, and S. DC, "Modelling and Simulation of Below-the-Hook Lifting Device Balanced C-hook for Load to Investigate the Static and Model Analysis for Various Grades of Steels by Numerical Method", J. Mod. Sim. Mater., vol. 3, no. 1, pp. 61-69, Jul. 2020. https://doi.org/10.21467/jmsm.3.1.61-69

\section{References}

[1] C. Asme, I. Provided, A. No, I. H. S. Licensee, and D. Energy, "Below-the-hook lifting devices," vol. 2003, 2006.

[2] A. S. of Mechanical, "Below the Hook lifting devices." p. 5, 2010, doi: ASME B30.20 - 2010.

[3] P. S. R. W. Sarvesh A. Mehendale, "Design and Analysis of Eot Crane Hook for Various Cross Sections," Int. J. Curr. Eng. Sci. Res. ( IJCESR), no. 12, pp. 53-58, 2016.

[4] G. Bhagyaraj, K. Suryaprakash, K. S. Rao, and C. A. D. Cam, “Crane Hook Design and Analysis,” Int. Res. J. Eng. Technol., vol. 4, 
no. 9, pp. 61-65, 2017, [Online]. Available: https://irjet.net/archives/V4/i9/IRJET-V4I912.pdf.

[5] E. S. Krishna and S. S. Kumar, "Design and analysis of crane hook with different materials," Int. J. Mech. Eng. Technol., vol. 9, no. 4, pp. 786-791, 2018.

[6] Govind Narayan Sahu1, "Design and Stress Analysis of various cross section of Hook," Ijmer, vol. 3, no. 4, pp. 2187-2189, 2013, [Online]. Available: http://www.ijmer.com/papers/Vol3_Issue4/CC3421872189.pdf.

[7] C. N. Benkar and N. A. Wankhade, "Finite Element Stress Analysis of Crane Hook With Different Cross Sections," Int. J. Technol. Res. Eng., vol. 1, no. 9, pp. 868-872, 2014.

[8] C. N. Benkar and P. N. A. Wankhade, "Design and Analysis of Crane Hook - Review," vol. 3, no. 1, pp. 2818-2822, 2014.

[9] G. Bhushan, "Design and Stress Analysis of Ramshorn Hook with Different Cross Section using CAE Tools," vol. 4, no. 1, pp. 1-8, 2017.

[10] Y. Torres, J. Gallardo, J. Domínguez, and F. J. E, "Brittle fracture of a crane hook," Eng. Fail. Anal. - ENG Fail ANAL, vol. 17, pp. 38-47, Jan. 2010, doi: 10.1016/j.engfailanal.2008.11.011.

[11] S. November, D. Revisions, T. Subject, and A. Codes, "B30.9-201x," no. November, 2017.

[12] ASME - American Society of Mechanical Engineers, “Asme B30.10,” no. February, p. 17, 2014.

[13] LA Joseph et al, "Structural Analysis Of Crane Hook," Int. J. Emerg. Technol. Comput. Sci. Electron., vol. 12, no. 2, pp. 108-111, 2015 .

[14] The American Society of Mechanical Engineers, "Design of Below-the-Hook Lifting Devices," vol. $2008,2006$.

[15] Y. B. Chunkawan and R. S. Subramaniyam, "Static Structural Analysis Of Crane Hook," Int. Res. J. Eng. Technol., vol. 4, no. 7, pp. 2265-2274, 2017, [Online]. Available: https://irjet.net/archives/V4/i7/IRJET-V4I7463.pdf.

[16] P. Lengvarský, M. Mantič, H. Róbert, and R. Huňady, "Design and strength analysis of C-hook for load using the finite element method," MATEC Web Conf., vol. 313, p. 00034, 2020, doi: 10.1051/matecconf/202031300034.

[17] O. Zienkiewicz and R. Taylor, The Finite Element Method, vol. I. 2005.

[18] K. N. A. Mahanthesh MR, Prashanth.R.Kubasad, "Numerical Analysis for a Bicycle Frame made of Mild Steel and Composite," Int. J. Sci. Eng. Dev. Res. (www.ijrti.org), ISSN2455-2631, vol. 3, no. 4, pp. 40-46, 2018, [Online]. Available: http://www.ijrti.org/papers/IJRTI1804008.pdf.

\section{Publish your research article in AIJR journals- \\ * Online Submission and Tracking \\ * Peer-Reviewed \\ * Rapid decision \\ * Immediate Publication after acceptance \\ * Articles freely available online \\ * Retain full copyright of your article. Submit your article at journals.aijr.in}

Publish your books with AIJR publisher-

* Publish with ISBN and DOI.

* Publish Thesis/Dissertation as a Book.

* Publish Monograph.

* Publish Edited Volume/ Book.

* Publish Conference Proceedings

* Retain full copyright of your books. Submit your manuscript at books.aijr.org 